\title{
ARTICULACIÓN DEL SISTEMA DE EDUCACIÓN SUPERIOR EN CHILE: POSIBILIDADES, TENSIONES Y DESAFÍOS*
}

\author{
Marcela Gaete ${ }^{1}$, Raquel Morales ${ }^{2}$
}

\section{RESUMEN}

El artículo presenta los principales resultados de un estudio que tuvo como propósito analizar y comparar los nudos críticos y alcances de la implementación de diversas modalidades de flexibilidad curricular -articulación, prosecución y continuidad de estudios- entre los niveles técnico superior, profesional y universitario que permitiera establecer ejes clave para el diseño de políticas y planes de acción en torno a un sistema de educación superior chileno organizado, pertinente y flexible. La metodología consistió en el estudio de casos múltiple y las técnicas de recolección de datos fueron el análisis documental y la entrevista en profundidad a gestores responsables de coordinar las iniciativas.

Los resultados alcanzados dan cuenta de una gran heterogeneidad de propuestas que comparten dificultades comunes relacionadas principalmente con la estructura, regulación, incentivos y financiamiento del sistema de educación superior.

Palabras clave: educación superior, articulación de estudios, flexibilidad curricular

\section{DEVELOPMENT OF THE HIGHER EDUCATION SYSTEM IN CHILE: POSSIBILITIES, TENSIONS AND CHALLENGES}

\section{ABSTRACT}

This article presents results from a study aimed to analyze and compare the critical nodes and the extent of implementation of several modalities of curricular flexibility -articulation, prosecution and study continuity-among the higher technical, professional and university levels in order to establish key axes for designing policies and action plans around an organized, appropriate and flexible Chilean Higher Education System.

The methodology involves numerous case studies and data collection methods, documentary analysis and extensive interviews with managers responsible for coordinating initiatives.

Outcomes refer to a major heterogeneity of proposals sharing common difficulties mainly related to structure, regulation, incentives and financing of the higher education system.

Keywords: higher education, articulation, curricular flexibility

* Proyecto que contó con el apoyo financiero del Consejo Nacional de Educación (CNED).

1 Académica Departamento de Estudios Pedagógicos. Universidad de Chile. Santiago, Chile.

2 Vicerrectora académica. Instituto Profesional AIEP. Santiago, Chile.

Contacto: raquel.morales@aiep.cl 


\section{ARTICULACIÓN DEL SISTEMA DE EDUCACIÓN SUPERIOR EN CHILE: POSIBILIDADES, TENSIONES Y DESAFÍOS}

\section{Introducción}

Desde fines del siglo XX, la educación superior ha experimentado a nivel mundial un proceso de construcción y reconstrucción, debido a los constantes cambios políticos, sociales, económicos y laborales. Al respecto UNESCO (1998) señala que la educación terciaria debería experimentar procesos de transformación que permitieran responder a las necesidades sociales, fomentar la solidaridad, la igualdad y colocar a los estudiantes en el centro, de tal manera de otorgar posibilidades de una educación a lo largo de la vida.

Una serie de autores (Álamos, 2002; OCDE, 2008; Bendersky, 2009 , entre otros) señalan que la necesidad de una educación permanente podría hacerse efectiva a través de la integración del sistema educativo, que permitiría a los sujetos transitar entre los niveles de formación de manera más fluida y de acuerdo a sus propios intereses y necesidades. Así, algunos países han asumido el diseño de un marco nacional de reconocimiento de aprendizajes previos, que facilita el paso entre niveles y la transferibilidad de los mismos. Esto ha sido posible por la adopción de los principios de una educación por competencias, la que no limita ni restringe de manera lineal el aprendizaje, sino que lo aborda de manera abierta, flexible y compleja.

En Chile aún es incipiente la adopción de un enfoque por competencias y no se cuenta con un marco nacional de reconocimiento de aprendizajes previos. Por el contario, las instituciones funcionan de forma independiente en materia de propuestas formativas y solo a partir de los años 90 se puede hablar en propiedad de un sistema de educación superior. Esto, porque hasta los años 80, la educación terciaria se limitaba a un reducido número de instituciones con 
una oferta académica restringida, dirigida a un pequeño número de personas, que en su mayoría, pertenecían a los sectores más acomodados de la sociedad. Según datos del Ministerio de Educación, en 1980 existían 8 instituciones de educación superior -todas universidades-. En 2010 esa cifra aumenta a 153 instituciones, de las cuales 39 eran institutos profesionales (en adelante IP), 57 centros de formación técnica (en adelante CFT) y 57 universidades.

A pesar del gran número de IP y CFT, la matrícula se concentraba en el nivel universitario. Según datos del MINEDUC, año 2010, el 63\% de la matrícula se concentró en las universidades; el 23,9\% en IP y el 13,1\% en CFT. Esto muestra el aumento de la oferta de programas de formación de nivel no universitario en instituciones privadas, pero menor matrícula en relación con la demanda total de los estudios universitarios. A esto se suma que no hay una regulación respecto a la oferta de programas en relación con las necesidades del país, que requeriría, según Meller y Rappoport (2004), formar más técnicos y profesionales en relación al actual desarrollo productivo de Chile.

Por otra parte, el sistema de educación terciaria se estructura en tipos de instituciones (CFT, IP y universidades) y en niveles cerrados (técnico, profesional y profesional con licenciatura) orientados por fines bien definidos y jerarquizados, considerados cada uno de ellos como niveles terminales y cuya arquitectura supone "un principio de diferenciación jerárquica que sitúa a las universidades en la cúspide del sistema, facultándolas para ofrecer cualquiera de los tres tipos de programas de pregrado" (MINEDUC, 2009:29). Mientras que los IP pueden impartir carreras profesionales sin licenciatura y programas técnicos de nivel superior y los CFT solo carreras técnicas.

Una de las consecuencias de dicha estratificación es la generación de una línea divisoria entre títulos similares, que afecta "tanto el prestigio social como los derechos legales de quienes obtienen estos títulos" (OCDE, 2009:171). A pesar de lo arraigado de esta estructura en nuestro país no hay una clara evidencia, como lo señala el estudio OCDE (2009), para afirmar de antemano que una universidad esté en condiciones de entregar los tres tipos de titulaciones y un instituto no. 
54 ARTICULACIÓN DEL SISTEMA DE EDUCACIÓN SUPERIOR EN CHILE: POSIBILIDADES, TENSIONES Y DESAFÍOS - Marcela Gaete, Raquel Morales

Diversos autores y organismos (Brunner y Meller, 2004; Salazar, 2005; Bernasconi, 2006; Comisión Presidencial sobre Educación Superior, 2009; OCDE, 2009) cuestionan esta organización del sistema educativo compartiendo alguna de sus problemáticas fundamentales: a) un "concepto de licenciatura obsoleto que genera barreras artificiales a la movilidad vertical para aquellos jóvenes que, habiendo cursado estudios técnicos o profesionales, desean acceder a programas de pre o posgrado dictados por universidades...; b) [ofrecimiento] de programas basados en el estatuto legal de las instituciones de educación superior y no en capacidades institucionales demostradas para ofrecer programas de formación técnica o profesional; c) falta de mecanismos y canales que faciliten la transferencia de alumnos dentro y entre instituciones de un mismo sector y nivel de formación profesional y entre instituciones de diferentes sectores y niveles" (MINEDUC, 2009:29-30).

Otro factor determinante en la arquitectura del sistema es el económico, porque los niveles están asociados a costos muy distintos. De tal modo, que los jóvenes de los sectores menos acomodados optan por una educación técnica, en virtud de las posibilidades de pago y, al contrario, los estudiantes de mayores recursos pueden optar a un número creciente de carreras universitarias. Todo esto en el contexto de una educación superior que no es un sistema organizado, sino que regulado por el mercado, lo que permite la dictación de una serie de carreras universitarias que incluso se encuentren con campos laborales saturados o viceversa (Uribe, 2004; Kremerman, 2005; OCDE, 2009). Nuestro país mantendría, así, un sistema de educación terciaria demasiado delimitado, en el que es muy difícil transitar de una modalidad formativa a otra por su falta de flexibilidad. Por el contrario, articular el sistema permitiría a los estudiantes de menos recursos - para quienes la oferta de programas de cinco años es poco pertinente- iniciar ciclos cortos habilitantes en competencias para ingresar al mundo laboral y/o para continuar hacia un segundo ciclo. Con ello se entregaría la posibilidad de acceso y titulación a muchos estudiantes que hoy no la tienen, superando problemas de movilidad social, equidad, retención, deserción, entre otros, y potenciando una educación a lo largo de la vida. 
Esto ha llevado a que el tema de la articulación del sistema se encuentre hoy en Chile en el debate nacional, siendo parte de la agenda del Foro para la Educación Superior (AEQUALIS) y se haya considerado en el Programa MECESUP II (2005-2012).

Las instituciones, por su parte, no se han quedado atrás y también han venido diseñando en estos últimos años iniciativas que permitan responder a las necesidades de articulación del sistema educativo terciario. Estas instituciones sin tener una homogeneidad de modalidades pedagógicas o institucionales, han desarrollado vías de articulación, salidas intermedias y planes especiales entre los niveles técnico y profesional, técnico y universitario, profesional y universitario -en varios casos de doble tránsito (universitariotécnico, universitario-profesional) - que han permitido interacciones de modalidades educativas distintas, cada una con sus propias especificidades y necesidades.

Sobre dichas experiencias no hay mayor información ni estudios que permitan considerarlas como referentes para una propuesta del sistema en su conjunto. Al respecto es relevante preguntar: ¿qué orienta conceptualmente estas propuestas? ¿Qué nudos problemáticos ha presentado su diseño e implementación según quiénes gestionan las iniciativas? ¿Cuáles son las experiencias comunes y diversas que presentan? En síntesis, ¿qué información relevante se puede levantar de las iniciativas implementadas que sirva de base para el diseño de políticas e implementación de nuevas iniciativas?

Para indagar en dichas interrogantes se planteó un estudio de casos múltiples de corte cualitativo, con el objetivo general de analizar y comparar los nudos críticos y alcances de la implementación institucional de diversas modalidades de flexibilidad curricular entre los niveles técnico superior, profesional y universitario que permita establecer ejes clave para el diseño de políticas y planes de acción en torno a un sistema de educación superior chileno organizado, pertinente y flexible. 


\section{Marco de referencia}

Diversos autores, (Neto Caraveo, 2002; Díaz Villa, 2002; Malagón, 2003; Rama, 2006, Bendersky, 2009, entre otros) concuerdan en que una de las orientaciones educativas fundamentales que debe asumir la educación superior es la flexibilidad, que implica centrar la mirada en los aprendizajes de los estudiantes, a los que se debe entregar mayor autonomía en la toma de decisiones respecto a su formación, tanto en los itinerarios, como en las formas de salida y entrada. Esto por las diversas demandas económicas (globalización, competitividad de los mercados), epistemológicas (ruptura de las fronteras disciplinarias), tecnológicas (nuevas formas de organizar y difundir el conocimiento), políticas (democratización de la sociedad) y sociales (búsqueda de una educación equitativa y de calidad) a las que debe responder la educación terciaria.

Las instituciones y los sistemas educativos pueden enfrentar el concepto de flexibilidad desde la perspectiva académica, administrativa, pedagógica o curricular. La primera, según Neto Caraveo (2002), implica nuevas formas de organización de las unidades académicas y de coordinación entre ellas. La segunda se centra en la flexibilización de normas, procedimientos, reglamentación, planeación y evaluación, por ejemplo, en términos de horarios, prerrequisitos, reglamentaciones de titulación y práctica, u otros. La tercera busca la innovación didáctica. La cuarta, según Malagón (2003), apunta a un proceso de apertura y reorganización entre los diversos elementos que constituyen el currículo, que permite que este tenga una cierta movilidad en su interior, lo que lleva a la diversificación de la oferta de cursos, planes de formación, vías de ingreso, reconocimiento de estudios previos, entre otros.

De este modo, diversas iniciativas pueden responder a los requerimientos de la flexibilidad curricular, entre las que pueden identificarse:

1. La articulación curricular: sintonización eficaz y coherente entre dos o más planes de estudio, de manera que mantienen entre sí algún movimiento o flexibilidad relativa, permitiendo salidas intermedias, múltiples vías de ingreso, movilidad horizontal y 
vertical entre programas del mismo o diferente nivel formativo. Para que esto pueda ocurrir es necesario que los planes de estudio de los niveles o carreras que pretenden articularse se diseñen en conjunto como un todo coherente. La articulación horizontal, por su parte, es la organización del currículo de un mismo nivel formativo, de tal manera que un plan de estudio no sea exclusivo de una carrera, ni tenga las mismas y únicas vías de entrada y salida, sino que pueda ser cursado por estudiantes de diversas carreras, facilitando el cambio de una carrera a otra y la doble titulación. Mientras que la articulación vertical refiere a las posibilidades de transitar fluidamente de un nivel a otro dentro del sistema educativo terciario y con reconocimiento del 100\% de los estudios previos, debido a que los programas formativos se encuentran armonizados curricularmente.

2. La continuidad de estudios. Unión natural que tienen entre sí los niveles de educación en el contexto de un continuo preestablecido legalmente. Así, la enseñanza preescolar, básica, media y superior serían las partes del continuo del sistema de educación de nuestro país. El paso de un nivel a otro está claramente normado y establecido en cuanto a certificaciones, condiciones de ingreso y egreso, legalidad y reglamentaciones. En cada uno de los casos se requiere una graduación o titulación previa, sin la cual no se puede acceder al nivel siguiente. A diferencia de la articulación, los planes de estudio de un nivel a otro no se encuentran sintonizados en un todo coherente, por los que son diseñados de manera independiente. Siguiendo lo señalado por Díaz Villa (2002), podemos caracterizar la continuidad de estudios al interior del nivel terciario como un conjunto de ciclos acreditados y habilitantes de ciertos desempeños que permitan la inserción laboral y que, además, son reconocidos como la base para iniciar el ciclo siguiente en cualquier institución del país.

3. La prosecución de estudios. Prolongación, extensión o reanudación de estudios en el mismo nivel formativo, o en otro, de tal modo que los estudios previos se consideran como una parte más del nuevo itinerario formativo y no como un ciclo terminado. Actúa por reconocimiento de asignaturas una a una, mediante procesos de convalidación y no requiere de título previo o de haber terminado un ciclo, como en los casos de continuidad y 
articulación, respectivamente. Solo flexibiliza la organización de las asignaturas -no todos los alumnos las cursan en el mismo orden-, los prerrequisitos, los horarios, vías de ingreso, tiempo de duración, reglamentos de convalidación de estudios, entre otros. Por lo que no siempre acorta los tiempos de titulación, como sí lo hacen los programas de articulación y continuidad.

Por su parte, en el ámbito internacional la mayoría de iniciativas en materia de flexibilidad curricular tienen en común la modularización de la formación, la determinación de competencias de egreso, la posibilidad de créditos transferibles (incluyendo la concesión de cualificaciones parciales), el reconocimiento de competencias adquiridas en el mundo laboral; lo que en su conjunto contribuye a implementar mejores rutas de progreso horizontal y vertical en todo el sistema de formación profesional. Generalmente, este conjunto de medidas dan lugar a sistemas de cualificaciones, entendidos como "todos aquellos dispositivos de un país que dan lugar al reconocimiento de una formación o un aprendizaje. Incluyen medios para diseñar y operar políticas nacionales o regionales de cualificaciones, disposiciones institucionales, procesos de garantía de la calidad, procesos de evaluación y titulación, reconocimiento de destrezas y otros mecanismos que vinculan el ámbito educativo/ formativo con el mercado de trabajo y la sociedad civil" (OCDE, 2008:27).

Un estudio sobre los sistemas nacionales de cualificaciones de la Unión Europea realizado por el Ministerio de Trabajo y Asuntos Sociales de España, concluyó respecto a estos sistemas que:

1. Cada país diseña su propio sistema de cualificaciones y formación profesional, de acuerdo con las necesidades de su cultura, historia, demandas sociales, cambios en la economía y en los sistemas de producción de bienes y servicios.

2. Los gobiernos han implementado una serie de medidas para favorecer la convergencia entre la educación general, la formación profesional y el aprendizaje adquirido en la experiencia laboral.

3. La aceptación y credibilidad social del sistema tiene su fundamento en dos factores clave: "La participación social de los actores en los diversos procesos de gestión de las cualificaciones y en crear 
una espiral de calidad en los instrumentos, procesos y acciones para llevar a cabo la implantación del sistema" (p. 162).

4. Los organismos que dirigen y coordinan los sistemas de cualificaciones y formación profesional son muy diversos tanto en su estructura como en sus funciones, algunos regulados por una autoridad nacional de cualificaciones (Francia), un consejo ministerial (Australia), un organismo autónomo (Nueva Zelanda), un organismo público (Gran Bretaña), entre otros.

5. Es necesario determinar y normalizar las cualificaciones que rigen para todo el país, lo que otorga transparencia y credibilidad a los sistemas.

6. Existe una tendencia hacia un sistema de reconocimiento, evaluación y certificación de la competencia independiente de su forma de adquisición, para la cual es indispensable contar con procesos de aseguramiento de la calidad.

7. Los sistemas de cualificaciones están basados en los créditos de aprendizaje que aseguran la movilidad de las personas.

8. Se debe construir a partir de las tradiciones respecto a quién es el organismo encargado de certificación y acreditación de la formación profesional.

9. La información y orientación son claves para optimizar la eficacia y eficiencia del sistema.

En el caso de Chile, la experiencia más cercana a un sistema de cualificaciones es la del Programa de Desarrollo Permanente de Chilecalifica-SENCE, en funcionamiento hasta el año 2009, que avanzó en la definición de un marco de competencias laborales en diversos sectores, tanto a nivel de los perfiles como de las respectivas unidades de competencias.

No obstante, la articulación de estudios bajo la modalidad de un sistema de cualificaciones presenta algunas limitaciones, pues no es instrumentalmente sencilla, ya que implica cambios profundos en la reglamentación, criterios de acreditación y evaluación, estructuración del currículo, espacios disciplinarios -en tanto paradigmas dominantes en las disciplinas- requisitos de admisión, exigencias de reconocimiento y certificación de los estudiantes. Es decir, aspectos 
60 ARTICULACIÓN DEL SISTEMA DE EDUCACIÓN SUPERIOR EN CHILE: POSIBILIDADES, TENSIONES Y DESAFÍOS - Marcela Gaete, Raquel Morales

relacionados con la organización estructural de las instituciones de educación superior.

\section{Metodología}

La presente investigación se propone como un estudio exploratorio comparativo de corte cualitativo, basado en el estudio de casos múltiples, que se emplea como una herramienta para estudiar (describir, analizar) una situación social contemporánea que se encuentra al interior de un fenómeno complejo que aún no se ha teorizado y donde no hay suficiente información sistematizada. Además, donde las fronteras entre el fenómeno y su contexto no están claramente identificadas (Stake, 1994).

Se optó por el estudio de cuatro casos porque un número mayor podría constituir dificultades de configuración y saturación (Martínez, 2006). La selección de los casos se basó en la determinación de criterios comunes y de máxima variación. Para los prímenos, se consideraron experiencias solo de instituciones autónomas, cuyos programas fueran de divulgación pública, y que sus autoridades las reconocieran como iniciativas de articulación de estudios vigentes, cuyas modalidades fueran internas en dos casos e interinstitucionales en los otros. Para los segundos, se consideraron: iniciativas de la Región Metropolitana y provincia, alojadas en diversos tipos de instituciones CFT, IP y universidades y entre distintas modalidades (técnica-profesional, técnica-universitaria, profesional-universitaria), con distintos años de antigüedad y diversos procedimientos.

En la tabla $n{ }^{\circ} 1$ se señala la configuración final de los casos. La columna 2 muestra la constitución del caso a partir de las instituciones que alojan las iniciativas y la columna cinco las diversas modalidades que coexisten paralelamente. 


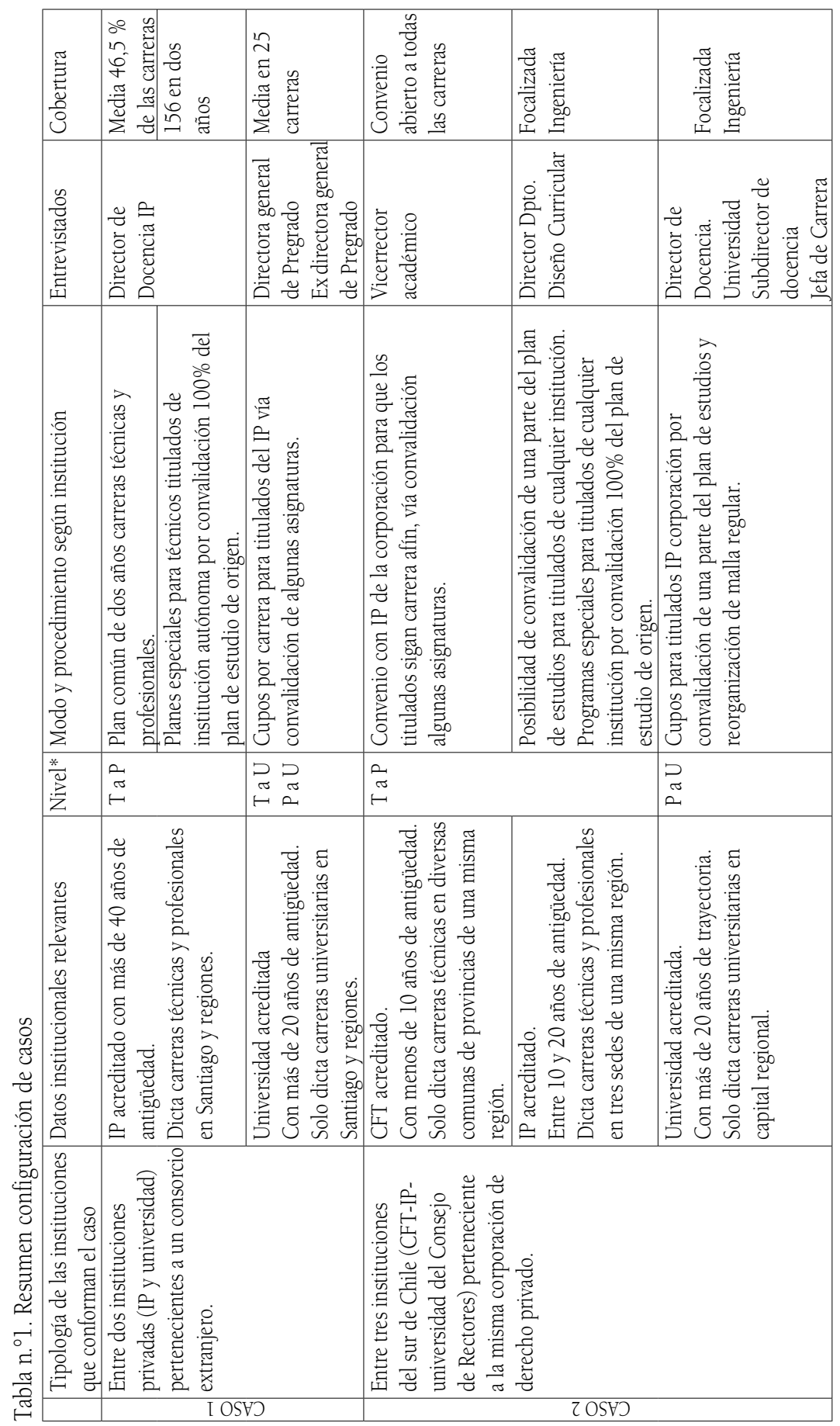


62 ARTICULACIÓN DEL SISTEMA DE EDUCACIÓN SUPERIOR EN CHILE: POSIBILIDADES, TENSIONES Y DESAFÍOS - Marcela Gaete, Raquel Morales

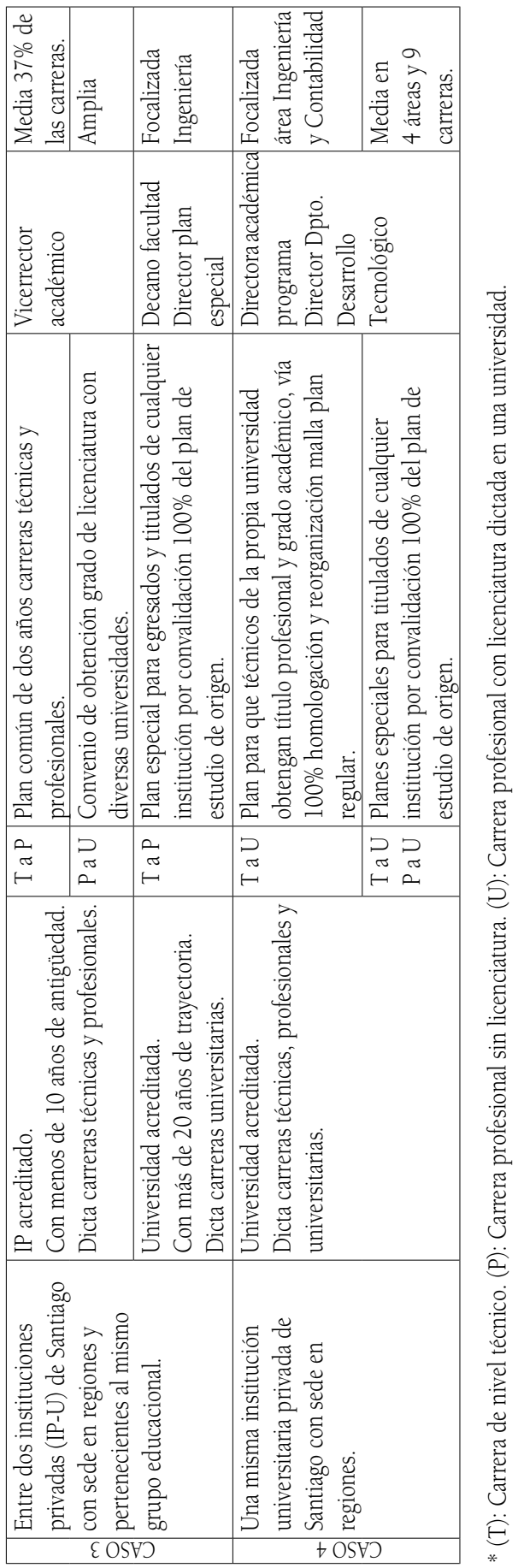


Las principales herramientas de recogida de datos fueron documentos institucionales (mallas curriculares, decretos, reglamentaciones, convenios) y entrevistas realizadas a doce gestores responsables de algún programa de flexibilización curricular. Los datos fueron analizados según el método comparativo constante, que consiste en la identificación de núcleos de significados en virtud del levantamiento de categorías inductivo-deductivas y por la triangulación de fuentes que permite el establecimiento de semejanzas y diferencias.

Sintéticamente el procedimiento general de la investigación fue el siguiente:

1. Revisión de las páginas web de todas las instituciones autónomas del país e identificación de aquellas que declaran algún tipo de flexibilidad curricular. Este proceso arrojó que 12 instituciones del país -siete IP y cinco CFT- declaran articulación de estudios interna o externa, ya sea con uno o más IP, CFT y/o universidad. En el caso de estas últimas todas las que imparten niveles profesionales o técnicos declaran algún tipo de flexibilidad (académica y/o financiera) para transitar entre niveles. Las instituciones que se articulan pertenecen tanto a los mismos grupos educacionales como a distintas corporaciones privadas y/o estatales.

2. Selección de programas que involucraran una, dos o más instituciones de Santiago y entre distintos niveles, e invitación formal a participar en el estudio. Este procedimiento se repitió en varias oportunidades en vistas de que no se obtuvo respuesta afirmativa de todas las instituciones.

3. Diseño de entrevistas, aplicación, transcripción y validación de las mismas por los entrevistados.

4. Análisis de datos mediante triangulación interna y transversal. En el primer proceso se contrastaron las entrevistas de los gestores institucionales ( 2 o 3) con los documentos oficiales para cada uno de los casos. En el segundo se cruzaron los datos productos de la triangulación interna, centrando el análisis tanto en los puntos en común como en las divergencias. Con esto se obtuvo una descripción intrínseca caso por caso y también un cruce horizontal que permitió el establecimiento de regularidades o patrones. 
64 ARTICULACIÓN DEL SISTEMA DE EDUCACIÓN SUPERIOR EN CHILE: POSIBILIDADES, TENSIONES Y DESAFÍOS - Marcela Gaete, Raquel Morales

\section{Resultados}

Uno de los resultados clave en el estudio de casos es identificar conceptualmente de qué trata el caso. Cuestión que no estuvo exenta de dificultades porque las diversas fuentes nombraban las iniciativas de flexibilidad con terminologías y caracterizaciones distintas, incluso al interior de una misma institución. De este modo, un mismo programa era denominado como articulación, prosecución, continuidad, plan especial, plan de continuidad y otros.

En consideración a la polisemia semántica y a la gran diversidad de procedimientos de implementación se decidió denominar los casos según su semejanza con las definiciones del marco referencial del estudio. Para ello se procedió a caracterizar los casos e identificarlos según clase (género) y diferencia específica, de acuerdo con los siguientes criterios:

a. Se consideró de forma genérica que un caso de articulación es aquel donde los planes de formación de dos carreras se encuentran integrados, de tal modo que un conjunto de asignaturas de un plan más ciertos requisitos de titulación dan lugar a un título técnico o profesional, y esos mismos ramos más otros dan lugar a otra titulación. En cambio, un caso de prosecución de estudios es aquel donde se reconoce solo un porcentaje de los estudios previos, de tal modo que sumadas otras asignaturas se obtiene un título de un nivel superior, igual o inferior de estudios. Finalmente, la continuidad implicaba el reconocimiento de título o egreso previo, de tal manera que en menor tiempo se obtiene una titulación de nivel superior.

b. Como las características diferenciadoras entre los casos eran en varios aspectos, se decidió focalizar en la concreción curricular de las propuestas, es decir, en el tipo de planes de estudio, por ejemplo, si correspondía a un plan común, planes especiales, plan regular, plan de licenciatura, etc.

De este modo se identificaron y diagramaron los cuatro casos en función a las modalidades implementadas como a las vías de ingreso. 


\section{Representación gráfica caso 1}

Prosecución a un plan regular, articulación por plan común y continuidad a un plan regular.

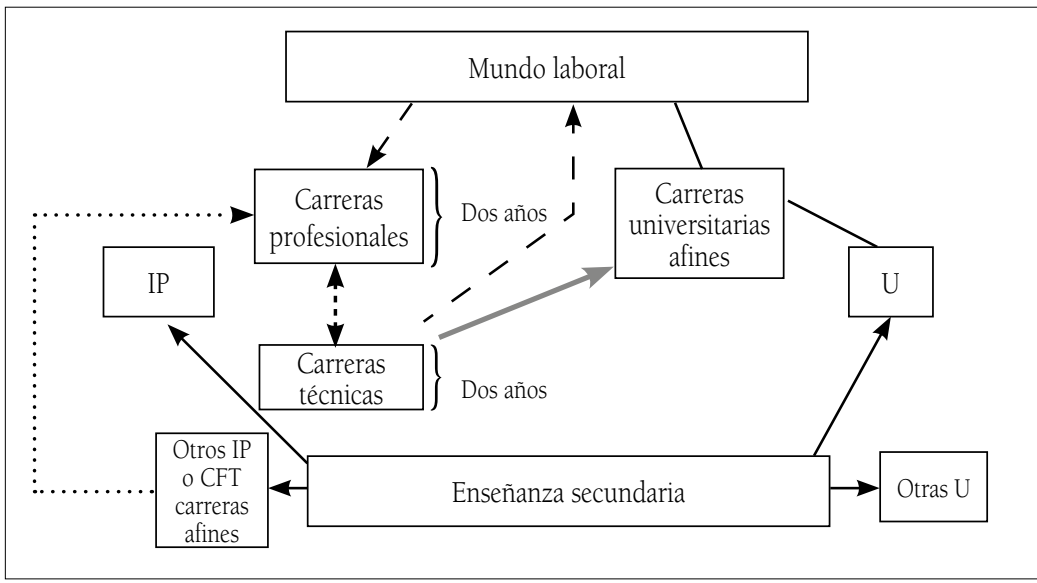

$4---\rightarrow$ Articulación Curricular por plan común. Homologación 100\%.

......... Continuidad a un plan regular para titulados de cualquier institución autónoma. Convalidación 100\%.

Prosecución a carrera afín universitaria. Convalidación de algunas asignaturas.

- $\quad \rightarrow$ Titulación ingreso mundo laboral y regreso a nivel profesional.

Representación gráfica caso 2

Prosecución por reorganización de un plan regular y continuidad vía planes especiales.

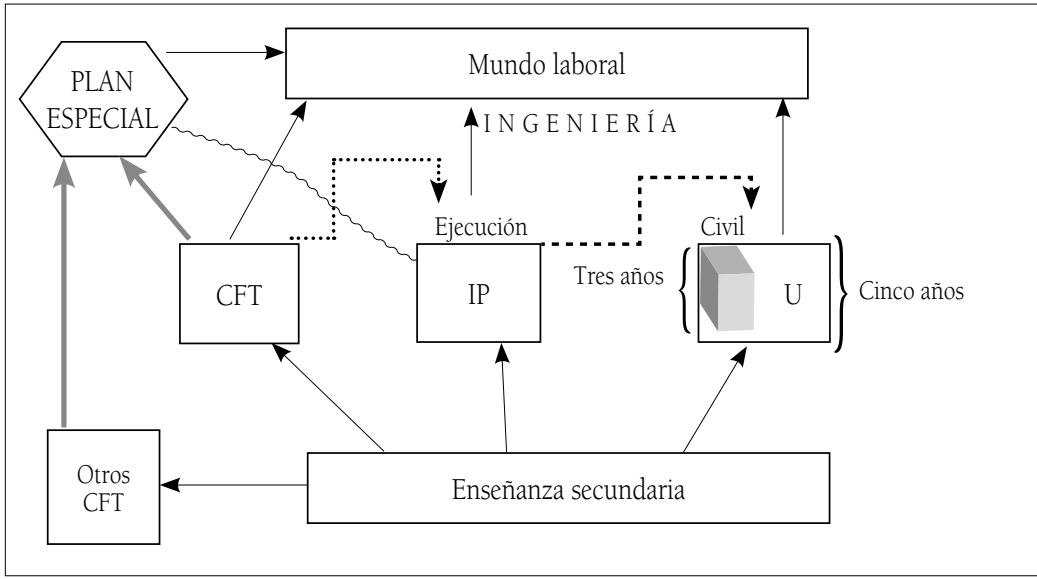

Prosecución por convalidación. Asignaturas a cursar organizadas en tres años.

........ Prosecución por convalidación solo algunas asignaturas.

Continuidad por convalidación 100\% carrera técnica. Reconocimiento de título Plan vespertino IP 
Representación gráfica caso 3

Continuidad vía planes especiales y articulación por plan común.

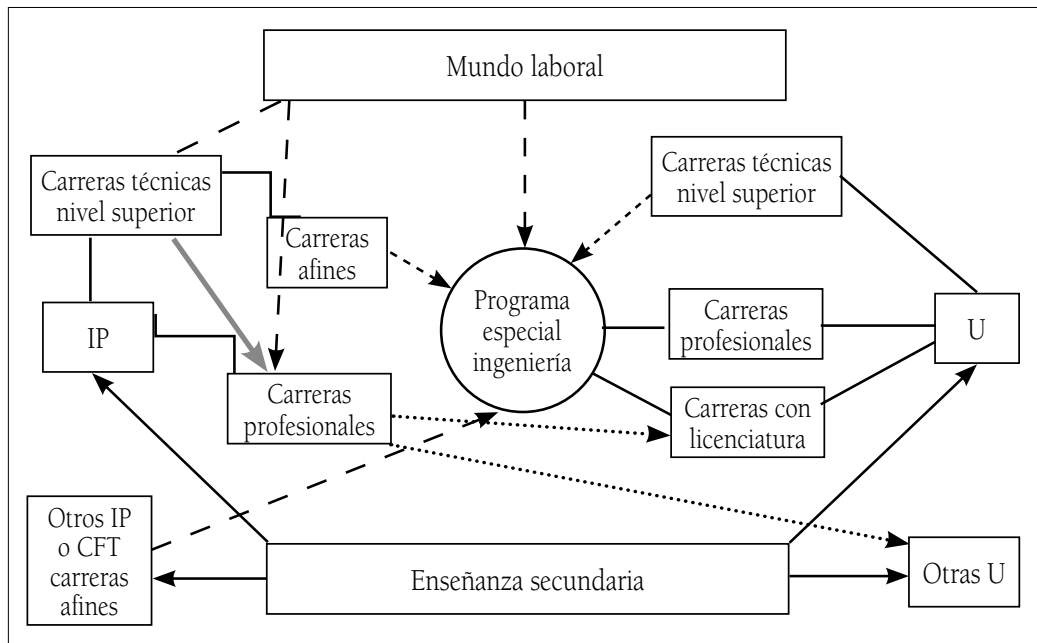

Continuidad interna plan especial. Homologación 100\%.

- $\rightarrow$ Continuidad externa plan especial. Convalidación 100\%.

.............. Continuidad obtención grado. Convalidación 100\%.

Articulación plan común. Homologación 100\%.

Representación gráfica caso 4

Articulación por reorganización plan regular y planes especiales de prosecución y continuidad de estudios

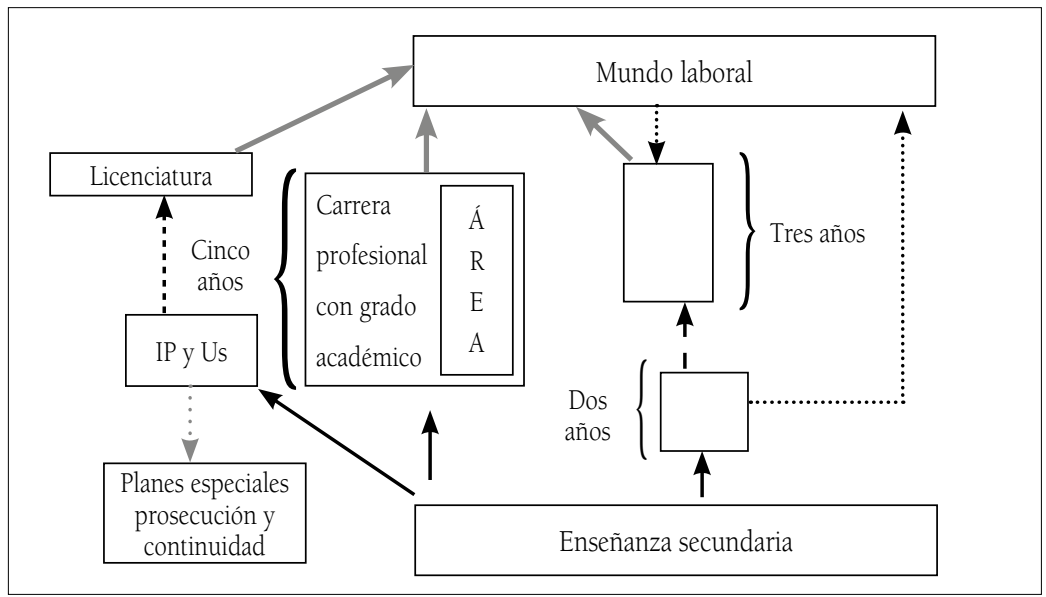

Continuidad vía obtención grado académico. Convalidación 100\%.

_ - $\rightarrow$ Articulación vía organización plan de estudio. Homologación 100\%.

…........ Ingreso mundo laboral título técnico y regreso a cursar plan de articulación. Homologación 100\%. Ingreso mundo laboral título profesional y grado académico.

........ Prosecución vía plan especial. Convalidación caso a caso, incluso 100\%. 
El análisis de cada caso y la posterior comparación entre ellos se organizó en cuatro categorías temáticas que arrojaron los siguientes resultados

\subsection{Antecedentes y contexto de la(s) experiencia(s)}

Uno de los aspectos comunes de las experiencias interinstitucionales de flexibilidad curricular es que se circunscriben a instituciones del mismo grupo educacional o consorcio, que ha comenzado las iniciativas en la medida en que el grupo educacional nacional o extranjero controla financiera y académicamente instituciones de diverso tipo (CFT, IP y U). Incluso, las iniciativas internas se desarrollan en la medida en que deben replantear el proyecto educativo institucional en vistas a las nuevas orientaciones. Solo en el caso cuatro, la iniciativa parte de un grupo específico de académicos de una facultad que explora posibilidades con una institución extranjera, específicamente de EE.UU., la que sirve de modelo para la iniciativa que se encuentra en desarrollo.

En relación con la antigüedad de las experiencias, estas son de corta data, ninguna con más de 10 años de experiencia. La más antigua corresponde a la prosecución de estudios del caso 2 iniciada en 2002, pero que ha tenido muy pocos alumnos y alta deserción, a la fecha con solo cinco titulados de los 16 matriculados. El resto corresponden a iniciativas de los últimos años, empezadas entre 2004 y 2010.

Cabe destacar que los CFT e IP son los que se muestran más interesados en iniciar procesos de flexibilización curricular, lo que se evidencia porque tienen en desarrollo diversas modalidades paralelas. Además, las iniciativas se encuentran explícitamente consignadas en sus páginas web, situación distinta a la de las universidades, que entregan una información muy escueta. Esta situación es diferente cuando se refiere a los planes especiales para titulados de cualquier institución, donde la información se encuentra claramente divulgada en las diversas instituciones. 


\subsection{Conceptualización, fundamentación y razones que originan las iniciativas}

Un aspecto común en la conceptualización de los cuatro casos es que el criterio de definición de una y otra modalidad está centrado en los requisitos generales de ingreso de los postulantes como asignaturas previamente cursadas, experiencia laboral, tipo de institución de procedencia (autónoma o no, perteneciente a la corporación o externa), años de egreso o titulación, rendimiento académico previo, etc., y no en las competencias que efectivamente son prerrequisitos de la nueva formación, a pesar de que la mayoría de las instituciones manifiesta estar desarrollando formación por competencias. Al respecto, sólo el caso 1 ha avanzado hacia esta definición a través de los diccionarios de competencias, que plantean los estándares de los niveles técnico y profesional.

Por su parte, los gestores institucionales señalan diversas razones que han servido de impulso para implementar las iniciativas de flexibilidad curricular, las que se consignan en la tabla n. ${ }^{\circ} 2$.

Tabla $n .^{\circ}$ 2. Síntesis de las razones para implementar las iniciativas

\begin{tabular}{|c|c|c|c|c|c|}
\hline \multirow{2}{*}{ Razones } & \multirow{2}{*}{ Descripción } & \multicolumn{4}{|c|}{ Casos } \\
\hline & & 1 & 2 & 3 & 4 \\
\hline Institucionales & $\begin{array}{l}\text { Por las políticas de cooperación al interior del grupo } \\
\text { educacional y/o asunción de criterios internacionales } \\
\text { de movilidad y flexibilidad }\end{array}$ & $\mathrm{x}$ & $\mathrm{x}$ & $\mathrm{x}$ & \\
\hline Sociales & $\begin{array}{l}\text { Movilidad social y la responsabilidad institucional } \\
\text { de entregar una formación con mayor equidad, al } \\
\text { diversificar las vías de ingreso y flexibilizar la dictación } \\
\text { de los planes de estudio, que permite a personas de } \\
\text { menos recursos combinar estudio y trabajo. }\end{array}$ & $\mathrm{x}$ & $\mathrm{x}$ & $\mathrm{x}$ & $\mathrm{x}$ \\
\hline Académicas & $\begin{array}{l}\text { Dar oportunidades de aprendizaje permanente, } \\
\text { cuestionamiento a la PSU como única vía de ingreso a la } \\
\text { universidad, mejoramiento de los índices de deserción } \\
\text { estudiantil en la medida en que se potencian salidas } \\
\text { intermedias, acortamiento de los tiempos de titulación, } \\
\text { posibilidad de doble titulación en Chile y el extranjero } \\
\text { y oportunidad de estudios profesionales o universitarios } \\
\text { a estudiantes destacados. }\end{array}$ & $\mathrm{x}$ & $\mathrm{x}$ & $\mathrm{x}$ & $\mathrm{x}$ \\
\hline Económicas & $\begin{array}{l}\text { Posibilidad rentabilizar el tiempo de los estudiantes, } \\
\text { viabilizar financieramente las carreras y evitar una pérdida } \\
\text { de recursos para el país, que en muchas ocasiones debe } \\
\text { solventar becas o créditos por largo tiempo }\end{array}$ & & $\mathrm{x}$ & & \\
\hline
\end{tabular}




\begin{tabular}{|c|c|c|}
\hline $\begin{array}{l}\text { Competitividad } \\
\text { en el mercado }\end{array}$ & $\begin{array}{l}\text { Entregar una oferta atractiva y la captación de matrícula } \\
\text { en el mercado de la educación superior. Permiten } \\
\text { ofrecer a los estudiantes alternativas de estudios que } \\
\text { posteriormente redunden en mejores puestos laborales. } \\
\text { Abrir posibilidades para que las carreras de IP compitan } \\
\text { con las carreras dictadas por universidades, al tener } \\
\text { convenios para la obtención de grado académico }\end{array}$ & $\mathrm{x}$ \\
\hline $\begin{array}{l}\text { Presiones } \\
\text { externas }\end{array}$ & $\begin{array}{l}\text { Resguardarse de las amenazas permanentes a las que se } \\
\text { ven sometidos los IP desde los colegios profesionales } \\
\text { y la legislación al no estar facultados para entregar un } \\
\text { grado académico. }\end{array}$ & $\mathrm{x}$ \\
\hline
\end{tabular}

\subsection{Estructura, procedimiento y cobertura}

El análisis de las diversas modalidades de flexibilidad curricular implementadas por las instituciones arrojan que:

a. En los cuatro casos estudiados, los sistemas de prosecución y continuidad de estudios que tienen carácter interinstitucional no se han constituido en modelos, entendidos como un diseño con procedimientos reglamentados y estandarizados, sino que su funcionamiento depende en mayor o menor medida de personas con cargos específicos que poseen sus propias adscripciones en relación con la formación, y quienes realizan las convalidaciones (por ejemplo, directores de carrera, comisiones ad hoc, etc.) o entregan los cupos disponibles (los que van cambiando de acuerdo con quien ejerza el respectivo cargo). Esto implica la fluidez o entorpecimiento de los convenios a los que adscriben las instituciones y vuelve frágil las iniciativas.

b. En todos los casos la modalidad de articulación curricular implementada tiene solo carácter interno y consiste en integrar las mallas de estudio, de tal modo que los estudiantes del nivel técnico cursen las mismas asignaturas del nivel profesional afín con la que se ha integrado para ello o bien cursan un plan común de dos años (casos 1 y 3) o bien cursan asignaturas que se encuentran distribuidas en diversos semestres del nivel profesional pero reorganizadas en dos años (caso 4). En todos los casos, los estudiantes ingresan directamente a la carrera de nivel técnico, profesional o universitario y luego proceden a solicitar un cambio de carrera. Por su parte, los estudiantes que no deseen continuar sus estudios deben realizar la práctica y rendir un examen para obtener 
el título técnico. En todos los casos se encuentra contemplado que el estudiante que se titula puede volver después de algún tiempo (generalmente no más de tres años) a continuar sus estudios en las mismas condiciones que consigna el plan de articulación.

Cabe señalar que la articulación funciona como cambio de carrera al interior de una institución. En el caso 3 inclusive pueden cambiarse en cualquier momento sin tener que haber completado los dos años. Esto hace que la lógica de articulación vertical no esté absolutamente instalada, lo que se comprende porque las instituciones se ven presionadas a mantener el ingreso a las dos carreras debido al financiamiento y a los sistemas de créditos y becas que exigen que las carreras profesionales estén acreditadas no así las técnicas. Lo que pone en mejores términos financieros a quienes optan por una carrera técnica que por una profesional, desincentivando la posibilidad de salidas intermedias desde un ingreso directo a las carreras profesionales, evitando así la duplicación de planes de formación.

c. El procedimiento en todos los casos es la convalidación y homologación de asignaturas, para lo cual las instituciones han procedido por una parte a flexibilizar los requisitos de convalidación, de tal modo de reconocer título previo de forma indirecta, sobre todo para el caso de los planes especiales o programas de continuidad a un plan regular como en el caso 1. Por otra, a homologar el $100 \%$ de las asignaturas a los estudiantes que cursan planes de articulación y que se cambian a una carrera afín. Las instituciones se han visto en la obligación de adaptar mecanismos tradicionales sancionados y validados -legal e interinstitucionalmente- para aplicarlos en estos nuevos contextos, puesto que no hay claridad a nivel del sistema de educación superior en relación con los procedimientos de reconocimiento de título o articulación de estudios por ciclo, menos aún se ha legislado para una formación por competencias, que está avanzado sobre todo en el nivel técnico y profesional. Por estos motivos, ninguna de las instituciones ha implementado sistemas de certificación de competencias previas.

d. En algunos de los casos (2 y 4) coexisten en una misma institución planes formativos de articulación, prosecución o 
continuidad que tienen exigencias curriculares muy diversas, a pesar de que entregan el mismo título profesional. Así, por una parte se realizan estudios de homologación o convalidación muy exigentes, en vistas de preservar la calidad de la formación y el perfil de egreso, y por otra, se dictan planes especiales vespertinos donde se aceptan titulados o egresados de cualquier institución, reconociéndoles el 100\% de los estudios previos. Esto redunda en el caso 2 en que todo el esfuerzo por lograr prosecución de estudios entre el CFT y el IP de la misma corporación, se pierda porque los egresados prefieren el plan especial, el cual es más conveniente porque lo realizan en menos tiempo y en jornada vespertina, lo que les permite trabajar. Además, el proceso contempla un riguroso proceso de convalidación, con exigencias de rendimiento, años de titulación y otros, lo que redunda en que los estudiantes del CFT de la propia corporación que postulan a la jornada diurna, encuentran más obstáculos que un egreso de otra institución si ingresa por continuidad a la jornada vespertina.

Algo similar ocurre en el caso 4, donde dos carreras son dictadas vía plan especial para titulados de cualquier institución y a la vez en una rigurosa modalidad de articulación, por la cual el programa del nivel técnico se conforma por asignaturas del plan de la carrera universitaria. De este modo, una misma institución entrega el mismo título profesional, en un caso resguardando el cumplimiento casi exacto del plan de estudio del plan regular y en otro caso no. Algo similar ocurre en el caso 1, que si bien no dicta un plan especial vespertino, reconoce título previo y permite que los estudiantes ingresen directamente a la carrera profesional al igual que aquellos que cursaron el plan común en la propia institución, lo que cuestiona la necesidad de un plan articulado, pues estudiantes con otras formaciones afines también estarían en condiciones de cursar la carrera profesional en dos años.

e. Las iniciativas interinstitucionales de prosecución de estudios, por las que los estudiantes de un nivel pueden cursar una carrera en otro o el mismo nivel, no incide necesariamente en acortar los tiempos de titulación. Esto, porque si bien existen planes de 
72 ARTICULACIÓN DEL SISTEMA DE EDUCACIÓN SUPERIOR EN CHILE: POSIBILIDADES, TENSIONES Y DESAFÍOS - Marcela Gaete, Raquel Morales

convalidación, estos varían entre 5\% y 35\%, dependiendo de la carrera, tal como en el caso 1.

f. En general, todas las modalidades de flexibilidad curricular tienen muy baja cobertura, ya sea porque han accedido pocos estudiantes o bien porque son pocas las carreras que están afectas a este sistema. En la modalidad de articulación el caso uno tiene $46,5 \%$ de las carreras afectas a mallas de articulación, en el caso 3 , el 38,2\% y en los casos 2 y 4 están adscritas solo carreras del área de Ingeniería. Difícilmente, en la modalidad de articulación las instituciones podrán llegar a coberturas del 100\% porque no dictan todas las carreras afines o porque hay áreas que se dictan solo en un nivel, ya sea técnico o profesional, o bien porque tienen restricciones legales para impartirlas porque son de exclusividad universitaria De los cuatro casos, el que tiene mayor cobertura es el caso 1, con 700 técnicos titulados que se han matriculado en seis años en una de las universidades del consorcio, de un total de 10.096 titulados en el periodo 2005-2010. En los otros casos las cifras son menores: en el caso 2, dieciséis alumnos se han matriculado en nueve años en el plan de prosecución entre el IP y la universidad, con solo cinco titulados; en el caso 3, veinte alumnos del IP han continuado hacia la obtención del grado de licenciado en dos años y cinco se matricularon en el plan de ingeniería civil. En el caso 4, si bien la matrícula asciende a 150 alumnos aún no han optado hacia la carrera universitaria, lo que no harán hasta diciembre de 2011.

\subsection{Fortalezas, debilidades y problemáticas identificadas por los gestores institucionales}

Los gestores institucionales señalan diversos nudos problemáticos presentes en las iniciativas de flexibilidad curricular, como lo muestra la tabla $n .^{\circ} 3$. Además, no explicitan, excepto en el caso uno, fortalezas en relación con los procedimientos con que se han implementado las diversas modalidades, sino solo destacan que sus instituciones son pioneras en la posibilidad de entregar oportunidades de equidad social, otorgando valor a las iniciativas como un punto de partida de la flexibilización del sistema de educación superior chileno. 
Tabla n. ${ }^{\circ}$ 3. Resumen nudos problemáticos identificados por los gestores.

\begin{tabular}{|l|c|c|c|c|}
\hline Nudos problemáticos & Caso l & Caso 2 & Caso 3 & Caso 4 \\
\hline Financiamiento & $\mathrm{x}$ & $\mathrm{x}$ & $\mathrm{x}$ & $\mathrm{x}$ \\
\hline Nivel socioeconómico de los estudiantes & $\mathrm{x}$ & $\mathrm{x}$ & $\mathrm{x}$ & $\mathrm{x}$ \\
\hline Perfil académico de ingreso de los estudiantes & $\mathrm{x}$ & & $\mathrm{x}$ & \\
Perfil estudiantes planes especiales vespertinos & $\mathrm{x}$ & $\mathrm{x}$ & $\mathrm{x}$ & $\mathrm{x}$ \\
\hline Cultura institucional & $\mathrm{x}$ & $\mathrm{x}$ & $\mathrm{x}$ & \\
\hline Gestión & & $\mathrm{x}$ & & $\mathrm{x}$ \\
\hline Diferencia de la calidad de la formación en distintas instituciones & & $\mathrm{x}$ & $\mathrm{x}$ & \\
\hline Racionalidad de las profesiones y & $\mathrm{x}$ & $\mathrm{x}$ & $\mathrm{x}$ & \\
Lógica de construcción de los planes de estudio & $\mathrm{x}$ & & $\mathrm{x}$ & $\mathrm{x}$ \\
\hline Falta de regulación del sistema de educación superior & $\mathrm{x}$ & & & \\
\hline Estructura del sistema de educación superior & & & $\mathrm{x}$ & $\mathrm{x}$ \\
\hline Estatus social de las carreras & & & \\
\hline
\end{tabular}

\subsubsection{Financiamiento}

La problemática referida al financiamiento es percibida por los gestores desde dos perspectivas, una relacionada con los costos institucionales que implica implementar las iniciativas de flexibilidad y otra relacionada con las posibilidades de financiamiento de los estudiantes. De acuerdo con la primera perspectiva, las instituciones que asumen el desafío de la flexibilidad curricular deben hacerse cargo de los costos implicados en los estudios de convalidación, integración de mallas o implementación de exámenes de competencia, para que ingresen vía especial un número reducido de estudiantes. Lo que no siempre es prioridad por la alta demanda de matrícula para ingreso vía regular.

Además, los estudiantes a los que van dirigidas las propuestas, generalmente, no cuentan con financiamiento para cursar estudios con aranceles que duplican o triplican los de su formación previa. No existen becas o créditos especialmente dirigidos a estudiantes de articulación, sobre todo para el caso de iniciar estudios en la universidad. Si a lo anterior se suma que el Crédito con Aval del Estado (CAE) no financia las prácticas profesionales, entonces tampoco se incentiva la obtención de titulaciones intermedias.

Por su parte, el 100\% de los CFT e IP en Chile son de carácter privado y la mayoría de las universidades que han comenzado con programas de flexibilidad curricular también lo son, de allí que 
requieren abrir programas que sean rentables y sustentables en el tiempo, pero siendo su principal fuente de financiamiento el arancel estudiantil, se les dificulta mantener los mismos costos entre las carreras técnicas y profesionales, como señala el gestor del IP del caso 3, o innovar con costos de operación demasiado altos (como en el caso 4). No se debe olvidar que en otros países, desde donde se han adaptado algunos modelos curriculares de articulación (caso 4), el financiamiento no solo está basado en los aranceles, sino que en donaciones, subvenciones $\mathrm{u}$ otros.

En este sentido, el financiamiento es un tema importante de resolver a la hora de optar por programas de articulación de estudios, de lo contrario las iniciativas se vuelven muy frágiles, tanto que los gestores del caso cuatro han considerado como opción que los estudiantes del nivel técnico rindan la Prueba de Selección Universitaria (PSU) al final del periodo, de manera que ingresen a los estudios universitarios por vía regular -optando a los beneficios financieros- y se proceda por homologación de asignaturas.

Una situación distinta se presenta en el caso uno, configurado por instituciones de gran tamaño, cada una con más de 12.000 estudiantes, que ha logrado mantener los mismos aranceles en el nivel técnico y profesional e incluso entregar una beca conducente a estudios en las universidades del consorcio, que mantiene el arancel técnico a lo largo de toda la carrera de continuidad. Se debe analizar si este modelo es factible en instituciones más pequeñas o con iniciativas focalizadas.

\subsubsection{Cultura institucional}

Un aspecto clave identificado por los gestores como nudo problemático es la cultura institucional, especialmente la universitaria, focalizada más en la transmisión de conocimiento que en el desarrollo de habilidades. Además, la creencia del profesorado y autoridades que la PSU es un buen predictor del éxito académico, redunda en resistencias hacia proyectos que consideran otras vías de ingreso.

Por su parte, hasta hace algunos años se concebía, al interior de las instituciones, que los diversos niveles de formación -técnico, 
profesional y universitario- constituían espacios independientes, cada uno con perfiles de egreso muy diferentes entre sí, lo que se ha visto potenciado por las acreditaciones de carreras, que no consideran criterios especiales para una formación por ciclos. Lo anterior incide, de acuerdo con algunos gestores, en las resistencias de ciertos miembros de la comunidad ante los diversos proyectos de flexibilización curricular. Prueba de ello, según los gestores del caso 4, es que su propuesta de articulación tuvo mayor acogida en una institución extranjera que reconoce los dos años cursados en Chile, que en instituciones nacionales con las que no se logró un acuerdo en este sentido.

\subsubsection{Gestión}

Representa un nudo problemático en la medida en que las instituciones de una misma corporación gestionan de manera independiente los procesos de flexibilización curricular. En el caso de los IP, es la vicerrectoría académica que centraliza las iniciativas y solicita a las instituciones en convenio los cupos. En el caso de las universidades, el proceso aunque se encuentre alojado en las direcciones de docencia, lo ejecutan las facultades, a través de jefes de carrera o coordinadores. De este modo, a pesar de la existencia de convenios marco, son los decanos o jefes de carreras los que toman la decisión de materializar o no el convenio institucional. Esta situación implica que las decisiones sean adoptadas por personas específicas que tienen sus propias visiones y adscripciones profesionales, por lo que los criterios cambian al interior de una misma universidad de carrera en carrera en relación a cupos, convalidaciones y otros. Lo que otorga cierta inestabilidad en el sistema, porque no cuenta con procedimientos estandarizados.

\subsubsection{Nivel socioeconómico de los estudiantes}

Los gestores institucionales manifiestan que la realidad socioeconómica de los estudiantes que ingresan al nivel técnico es un impedimento para la continuidad efectiva de los estudiantes a niveles superiores, pues muchos de ellos no cuentan con los medios económicos para costear estudios profesionales o universitarios con aranceles mucho más altos, y tampoco están en condiciones de dedicar cinco años de su vida a su formación profesional -incluso estando becados- 
porque deben colaborar con la mantención familiar, lo que implica que busquen carreras de dos años de rápida inserción laboral. Esta situación es generalizada en los estudiantes del caso 2, cuyo CFT tiene sedes en localidades regionales que presentan una alta cesantía.

Se debe tener presente que en Chile los estudiantes no eligen un tipo de educación o de institución solo por intereses y habilidades, sino por los costos asociados y el tiempo que pueden invertir en educación. De este modo, las propuestas de continuidad que permiten conciliar trabajo y estudio parecen más factibles que aquellas que requieren dedicación exclusiva diurna, lo que podría explicar el bajo interés por los programas de prosecución a programas regulares en los casos 2 y 3 .

Por otra parte, los gestores identifican la existencia de una significación social respecto al logro de un título profesional -muchas veces el primero en la familia- que obstaculiza las motivaciones de algunos estudiantes hacia la continuidad de estudios, pues ellos sienten que ya han logrado la gran meta familiar y personal.

En este mismo sentido, las expectativas de los estudiantes que ingresan a estudios de nivel técnico no siempre se condicen con las altas exigencias académicas de los programas de articulación en los dos primeros años. Así, en el caso 4 los estudiantes han solicitado una solución en vistas a que no todos desean continuar hacia el nivel profesional y tampoco se proyectan en la obtención de una doble titulación con EE.UU., por su realidad socioeconómica, que incluso les impide proseguir estudios en Chile. Así, de continuar con estas diferencias entre las expectativas de los estudiantes y los fundamentos del programa se corre el riesgo de tener menos interesados y con ello se fragiliza la futura viabilidad del programa.

\subsubsection{Lógica de construcción de los planes de estudio}

Un aspecto curricular fundamental que se cuestionan los gestores de tres de los casos y que tensiona las propuestas de articulación y continuidad de estudio son las lógicas de construcción curricular, que en la mayoría de los casos preceden a las nuevas tendencias y políticas institucionales de la articulación de estudios, y que están 
construidas con su propia lógica interna, como carreras terminales, basadas en conocimientos.

A su vez, la lógica de construcción curricular basada en una estructura por ciclos cortos consecutivos - uno inicial de dos años, equivalente al nivel técnico actual, más otro de dos años, equivalente al nivel profesional sin licenciatura $(2+2)$ - es cuestionada por los gestores institucionales, que basados en su experiencia discuten la validez de las propuestas curriculares que plantean que un profesional en Chile pueda formarse efectivamente por la adición de dos años de estudios profesionales a los dos años del nivel técnico ya cursados. Así, uno de los gestores del caso 2 discute que las competencias estratégicas, propia de las ingenierías, puedan desarrollarse en dos años, teniendo como prerrequisito competencias más bien operativas del nivel técnico. Esto porque la diferencia entre un técnico y un profesional radicaría en un cambio en la forma de enfrentar los problemas y por la adquisición de una cierta racionalidad de la profesión, la que en algunos casos sería difícil de desarrollar en dos años, sobre todo si se considera que los estudiantes que ingresan a nivel técnico, generalmente, tienen una formación secundaria que no ha potenciado el desarrollo de procesos cognitivos superiores, que sirvan de base a una formación más estratégica. En este sentido parece fundamental analizar cuánto tiempo demora en formarse cada una de las competencias que desarrollan las carreras de acuerdo con el perfil académico de ingreso de los estudiantes.

4.4.6 Falta de regulación del sistema de educación superior Hay consenso en tres de los casos, que una dificultad para el diseño e implementación de diversas propuestas institucionales en materia de flexibilidad curricular es la falta de políticas e incentivos formales que favorezcan la articulación entre los niveles de la educación superior terciaria. Razón por la cual las propias instituciones han tenido que adaptar y diseñar nuevos mecanismos que soporten el proceso. Debido a que la reglamentación existente más bien obstaculiza las iniciativas, pues no establece criterios ni mecanismos para el reconocimiento de estudios previos, ni tampoco legisla la posibilidad de una educación por ciclos, sino que solo vinculada a niveles de formación. 
78 ARTICULACIÓN DEL SISTEMA DE EDUCACIÓN SUPERIOR EN CHILE: POSIBILIDADES, TENSIONES Y DESAFÍOS - Marcela Gaete, Raquel Morales

\subsubsection{Estatus social de las carreras}

Un aspecto señalado como nudo problemático es la valoración social de las carreras universitarias por sobre las técnicas, siendo la aspiración de los estudiantes y sus familias ingresar a una institución universitaria. Además, ciertas carreras como ingeniería gozan de un alto prestigio, lo que explicaría por qué algunos estudiantes del caso 3 prefieren matricularse directamente en la carrera profesional, aunque implique pagar más por recibir el mismo servicio durante los dos primeros años, si la carrera está afecta a plan común de articulación.

Tal sobrevaloración de la institución universitaria y de ciertas carreras, es incentivada por los tipos de financiamiento asociados a la PSU y por el discurso social, político y ministerial que relaciona el éxito de las escuelas y los estudiantes con el ingreso a la universidad. Tal situación, de acuerdo con los gestores del caso 3, afecta la decisión de algunos estudiantes, que presentando problemas académicos o de otra índole, no aceptan articularse hacia abajo, es decir, estando en el itinerario universitario cambiarse al nivel técnico, porque simbólicamente es sinónimo de fracaso. Lamentablemente, en muchos casos implica la deserción del estudiante, con la concerniente pérdida de dos o tres años de estudios universitarios no certificados.

\subsubsection{Perfil académico de ingreso}

Otro aspecto considerado como un factor que obstaculiza las posibilidades para implementar planes de articulación o prosecución de estudio es la preparación con que ingresan los estudiantes a la educación superior. Dicha preparación en muchos casos es deficiente y diversa en su base, lo que provoca desigualdades en el perfil de ingreso de estudiantes de CFT, IP o universidad, difíciles de revertir en dos años de educación superior de nivel técnico. Desde esta perspectiva, una titulación de nivel técnico no siempre sería suficiente para que el estudiante ingresara directamente a segundo o tercer año de una carrera universitaria afín y tampoco garantía para terminar las carreras profesionales y universitarias con éxito.

La experiencia acumulada a la fecha por los gestores institucionales les permite aventurar que el sistema de articulación y 
continuidad de estudios no va a poder implementarse masivamente, sino que constituiría una posibilidad abierta solo para aquellos estudiantes mejor preparados. En este sentido, señalan que el sistema europeo de estudio por tramos y salidas intermedias es poco probable de aplicar en Chile, sin resolver previamente algunos problemas estructurales del sistema educativo nacional.

El perfil de los estudiantes también resulta una problemática en los planes especiales vespertinos, pues es difícil de manejar la heterogeneidad de las formaciones previas, experiencias profesionales y el poco tiempo con que cuentan los estudiantes para dedicar a su formación, afectando la calidad de los programas por la propia presión de los interesados.

\subsubsection{Diferencia de la calidad de la formación en distintas} instituciones

Un sistema de flexibilidad curricular requiere de confianza en la calidad de la formación que entregan las instituciones, que permita ampliar los convenios entre un gran número de centros de formación. Pero esta situación está lejos de darse en nuestro país, como señalan los gestores, por la heterogeneidad en la calidad de los programas de formación, que vuelven dudoso cualquier intento por homogeneizarla vía convenios de reconocimiento de título. Ante esta situación algunos planes especiales, como en los casos 3 y 4 han optado por agregar un semestre previo de nivelación.

De este modo, consideran que mientras no se pueda asegurar la calidad de las instituciones es mejor optar por modalidades de articulación de estudios al interior de cada institución, o bien, delimitar los planes especiales que reconocen títulos a convenios entre instituciones con niveles de formación acreditados por su calidad.

\subsection{Fortalezas y buenas prácticas}

De los casos estudiados, y por sobre las problemáticas identificadas, se advierten buenas prácticas, que deberían considerarse para la implementación de un sistema de educación superior articulado, entre estas: 
- Análisis riguroso de los programas de formación involucrados y elaboración del plan de articulación interinstitucionalmente (caso 4).

- Diseño de un sistema de financiamiento que permita el tránsito efectivo entre los niveles (caso 1).

- Confección de diccionarios de competencias que permitan articular la formación técnica y profesional de manera coherente y cohesionada (caso 1).

- Coordinación centralizada de todos los programas de flexibilización curricular, que permita establecer criterios comunes y consolidar un modelo, y no hacerlo depender de facultades, departamentos o carreras de forma separada (casos 1 y 3 ).

\section{Conclusiones y propuestas}

\subsection{Conclusiones}

- Las instituciones participantes en el estudio se encuentran realizando grandes esfuerzos por implementar iniciativas de flexibilidad curricular, pero se enfrentan a una serie de obstáculos a raíz de que la educación superior en Chile no está organizada y regulada para ello. Consecuentemente, se ven en la obligación de adaptar normativas y responder a criterios de financiamiento, acreditación de carreras, estatuto legal de las instituciones para entregar certificaciones, entre otras, que no están a la altura de las iniciativas de flexibilidad curricular. Por ejemplo, en el establecimiento de ciclos, reconocimiento de estudios previos, determinación de competencias profesionales, entre otras. Esto redunda en que las iniciativas de articulación entre el nivel técnico y profesional de una misma institución, que acortan los tiempos de titulación, aún no puedan plantearse como ciclos consecutivos, sino como carreras paralelas. De este modo es muy difícil que se instale la noción de formación a lo largo de la vida.

- Las instituciones que han implementado iniciativas en la materia, lo hacen en su mayoría solo mediante convenios entre las instituciones pertenecientes al mismo grupo educacional, de tal modo que es bajo sus propias orientaciones y de manera aislada 
lo que genera una gran heterogeneidad de propuestas, que de aumentar van a acrecentar la polisemia, los procedimientos y las problemáticas en relación con el aseguramiento de la calidad de los programas. Esto hará más difícil el diseño de un sistema nacional de reconocimiento de competencias. Aspecto fundamental que debe asumirse a nivel nacional, y no por las instituciones aisladamente, de acuerdo a las experiencias internacionales.

- La obsolescencia de la estructura del sistema de educación superior diagnosticada por organismos como la OCDE (2009), redunda en que instituciones diseñadas con propósitos diferentes se vean en la obligación de competir de forma desigual y no a colaborar entre sí. En este contexto las universidades presentan ventajas comparativas: a) el grado de licenciatura; b) la valoración simbólica de pertenecer a la población que ha logrado ingresar a la universidad (aunque esta no esté acreditada o sea de dudosa calidad); y c) Más y mejores sistemas de financiamiento. Lo que se transforma en un nudo problemático a la hora de proponer iniciativas de cooperación en materia de flexibilidad curricular.

- La arraigada valoración social de la institución universitaria como símbolo de éxito, incentivada desde políticas ministeriales que consideran como indicador de logro de la educación secundaria el puntaje PSU -y no el ingreso a la educación terciaria en general-, sumado a los criterios de financiamiento asociados y al nulo incentivo que tienen las universidades de abrir otras vías de ingreso, podría ser un obstáculo importante para iniciar un proceso de articulación del sistema educativo terciario, porque podrían haber pocos interesados en matricularse en ciclos formativos asociados a los niveles técnicos o profesionales, pues se aspira a ingresar inmediatamente a carreras universitarias, a pesar de que el campo laboral en algunas de ellas está prácticamente saturado y que falten técnicos de nivel superior.

- La alta segmentación de los estudios según nivel socioeconómico en el nivel secundario es heredada al nivel terciario, de tal modo que los estudiantes con menos recursos ingresan a los CFT y los de más altos a las universidades. Los primeros en 
muchos casos no tienen la capacidad financiera para dedicar cinco años solo a estudiar. Esto puede provocar, como en el caso 2, que los esfuerzos por articular programas finalmente no tengan interesados, al contrario de los planes especiales vespertinos que permiten combinar trabajo y estudio. Otro dato importante relacionado con la segmentación del sistema es que los estudiantes que ingresan generalmente al nivel técnico tienen una heterogénea y deficiente preparación previa, la que no alcanza a equipararse necesariamente al egreso, después de dos años, con la de un estudiante universitario de cuarto semestre. Lo que es un aspecto difícil de resolver para articular la formación técnica con la universitaria, en las condiciones actuales del sistema, y requiere cambios profundos, que no se resuelven únicamente en el diseño de las mallas curriculares.

- Un sistema de articulación de estudios en nuestro país tendría que fortalecer el crecimiento de CFT e IP, que permitiría el acceso a un sector de la población que no lo tiene en estos momentos y dar solución a la gran cantidad de estudiantes que se ven forzados a desertar de las universidades después de dos o tres años, cuyos estudios no son reconocidos, habiendo realizado una alta inversión. De lo contrario, la integración del sistema de educación superior se traduciría solo en una ampliación de los cupos de las universidades, vía ingreso especial, para unos pocos estudiantes, bajo el mecanismo de convalidación de asignaturas. Algo que siempre ha contemplado el sistema de educación terciario en Chile, pero ahora más extendido y formalizado a través de convenios entre instituciones.

- En la mayoría de los casos las propuestas de flexibilidad curricular son consideradas como una vía de ascenso social dirigida a unos pocos estudiantes talentosos de escasos recursos, para los que se crean condiciones (planes comunes, convenios de prosecución) que faciliten el cambio de carrera al nivel profesional o universitario o permitan a titulados o egresados de niveles anteriores en carreras afines, combinar estudio y trabajo. Pero no se concibe como una propuesta para los individuos en su conjunto, lo que se evidencia en que no hay iniciativas para que estudiantes que han cursado dos o tres años de estudios universitarios puedan 
por el reconocimiento de sus estudios obtener un título técnico en menos tiempo. En estos casos las propuestas no han logrado dar una solución a la deserción estudiantil ni acortar los tiempos de titulación.

- Los costos de la educación son muy altos, "el promedio de los aranceles es el 30\% del ingreso per cápita, tres veces más alto que en los Estados Unidos, Australia o Japón" (OCDE, 2009: 44) y solo el 46,4\% de lo quintiles más bajos reciben financiamiento. Esto es fundamental para fomentar iniciativas de educación permanente, porque si los alumnos no las pueden costear peligra la sustentabilidad financiera de programas cuya única fuente de financiamiento son los aranceles. El problema es complejo porque implica entregar más becas a instituciones privadas, no todas sin fines de lucro. Tema de debate nacional y cuya decisión debería adoptarse como país y con todos los actores involucrados. Al respecto, el IP del caso 1 presenta un modelo de financiamiento digno de considerar, porque logró equilibrar la sustentabilidad financiera de las carreras con el proyecto de equidad social, entregando una gran cantidad de becas institucionales consistentes en mantener el arancel técnico para estudios universitarios en las instituciones del propio consorcio a un número limitado de estudiantes talentosos y, además, establecer los mismos aranceles para las carreras técnicas y profesionales, lo que elimina el factor arancel como impedimento para la continuidad de estudios.

- Para el caso de iniciativas de flexibilidad curricular, las culturas institucionales, profesionales y locales juegan un papel central que pueden impulsar u obstaculizar las iniciativas. Esto indica que un sistema nacional de integración entre niveles, no solo debe considerar a los grupos que se encuentran desarrollando las iniciativas, y que por tanto son proclives a ellas, sino a una comunidad social más amplia como son los docentes, colegios profesionales y empleadores.

- Se requiere estudiar los tiempos que un estudiante chileno demora en adquirir ciertas competencias en relación con su perfil de ingreso. Esto es fundamental para decidir si en el contexto de la educación del país es pertinente una estructura 
de ciclos profesionales consecutivos $(2+2)$, y si estos a su vez, podrían ser propedéuticos de ciclos académicos (licenciatura, máster, doctorado). Así, por ejemplo, es importante determinar si las competencias investigativas entregadas en algunos planes especiales de licenciatura pueden adquirirse en un año, o si es posible que técnicos titulados de cualquier institución puedan adquirir en dos años las competencias del nivel siguiente.

- Es imprescindible estudiar las posibilidades efectivas que tienen las IES, que implementan algún programa de flexibilidad curricular, para asegurar el logro del perfil de egreso de los estudiantes que han cursado una parte de sus estudios en otros centros de formación, los que funcionan con lógicas educativas distintas y con diversos sellos institucionales. Además, los procesos de acreditación tendrían que considerar el factor de flexibilidad curricular como uno de los criterios valorables, permitiendo de este modo establecer estándares e indicadores de calidad. Esto es fundamental porque podría extenderse a nivel de país la situación de los planes especiales que otorgan el mismo título profesional que una carrera de plan regular, pero sin las regulaciones de esta última, dando lugar a que convivan en una misma institución programas de distinta categoría académica, con diversos perfiles de egreso efectivos, pero equivalentes en el título.

\subsection{Recomendaciones y propuestas}

Si bien es urgente avanzar hacia un sistema de cualificaciones para Chile, es imprescindible a corto plazo establecer las condiciones mínimas para que tal sistema pueda ser implementado con éxito, condiciones que otros países han tardado décadas en construir, entre estas: a) que la educación terciaria deba necesariamente regularse por criterios comunes y no por decisiones aisladas de instituciones en particular; b) que los sistemas de acreditación estén suficientemente consolidados y validados de tal manera que aseguren la calidad de la formación entregada; c) que exista vinculación entre el sistema educativo y el mercado laboral; d) que los estudiantes tengan equidad de acceso tanto por sus competencias previas adquiridas en la educación secundaria como por el acceso al financiamiento; e) que la 
cultura institucional esté abierta a considerar la necesidad y beneficios de una formación por ciclos; f) que los colegios profesionales y la sociedad en general también estén dispuestos a cambiar la estructura del sistema actual, sin menospreciar tipos de instituciones ni formaciones sino que valorando la posibilidad de aprendizaje durante toda la vida (OCDE, 2008)

Debido a lo anterior, se sugieren a continuación tres propuestas de políticas con sus acciones respectivas relacionadas con la creación de condiciones para que a mediano plazo se pueda comenzar a trabajar en el establecimiento de un sistema nacional de cualificaciones pertinente a la realidad del país. No se recomendarán políticas ni acciones con relación a cambios estructurales del sistema, puesto que estas ya se encuentran consignadas en el Informe sobre la Educación Superior en Chile (OCDE, 2009).

Las políticas y acciones que se proponen tienen relación con:

1. Mayor regulación del sistema actual

Acciones

1.1 Establecer un marco conceptual y legal que regule las iniciativas actuales y las que se implementarán antes que Chile cuente con un sistema de cualificaciones. Este marco tendría que considerar una terminología común (articulación, prosecución, continuidad, entre otras), establecer criterios mínimos para el reconocimiento de título previo, regular la posibilidad de formación por ciclos, y no exclusivamente por niveles.

1.2 Legislar la posibilidad de que cada institución realice un examen de competencias previas - que ella misma certifiquepara que el estudiante pueda ingresar a una carrera profesional o universitaria vía convalidación del perfil de egreso de la carrera de origen.

1.3 Crear un sistema de apoyo, seguimiento y evaluación de los programas especiales de prosecución o continuidad de estudios implementados por las instituciones. Para ello, se sugiere la creación de un sistema que concentre información de todos los programas actualmente vigentes en el país. 
2. Incentivar los estudios técnicos y profesionales y no solo los universitarios, como posibilidades de una educación a lo largo de la vida.

Acciones:

2.1 Establecer como indicador de calidad para las escuelas secundarias el ingreso a la educación terciaria en cualquiera de sus niveles y no solo a la universidad.

2.2 Diseñar becas especiales para estudiantes que ingresan a instituciones que estén implementando programas de articulación de estudios entre la formación técnica y profesional.

2.3 Incentivar a las universidades para diseñar vías de ingreso que no consideren únicamente PSU, sino también estudios técnicos o profesionales previos.

2.4 Revisar los sistemas de financiamiento asociados a acreditación de carreras, que consideren las carreras articuladas entre nivel técnico y profesional, como una situación especial, que permita a los estudiantes postular a financiamiento a pesar de que se matriculen en el nivel profesional, puesto que los dos primeros años son los mismos de la carrera técnica. Se sugiere, en estos casos, exigir la acreditación de carreras para renovar la beca al pasar al nivel profesional.

2.5 Considerar en el Crédito con Aval del Estado la posibilidad de salidas intermedias, financiando los procesos de práctica y titulación del nivel técnico y luego el financiamiento del nivel profesional.

2.6 Establecer criterios en la acreditación de carreras que incentiven la formación por ciclos entre el nivel técnico y profesional de una misma institución.

2.7 Incentivar a las universidades para que rediseñen sus planes de estudio, de tal forma que los dos primeros años puedan certificarse como un ciclo que habilita en ciertas competencias profesionales.

2.8 Sensibilizar a las instituciones, colegios profesionales, empleadores y sociedad en general, de la necesidad de una educación profesional por ciclos, en vistas de una mayor equidad y posibilidades de desarrollo de la ciudadanía. 
3. Financiar estudios y análisis de posibilidades de integración del sistema de educación superior

Acciones

3.1 Convocatoria especial de proyectos que entreguen propuestas de modelos de articulación del sistema de educación terciaria pertinentes a la realidad nacional.

3.2 Convocatoria a proyectos por área que incluyan a las diferentes instituciones para que determinen competencias de los diferentes niveles de formación, con la finalidad de que se transformen en un referente a nivel nacional. Se sugiere por ejemplo el área de ingeniería porque en la actualidad se encuentran vigentes diversos proyectos de flexibilidad curricular.

3.3 Convocatoria para analizar "buenas prácticas" en el tema de articulación de niveles y que han resuelto nudos críticos en el ámbito curricular y de financiamiento como en el caso 1.

3.4 Establecer en el fondo de innovación académica (MECESUP) fondos para que instituciones que estén realizando modalidades de flexibilidad curricular evalúen y mejoren sus programas.

3.5 Fortalecer en la agenda de educación superior (2011-2014) la línea estratégica de armonización curricular entre redes de instituciones pertenecientes a distintos consorcios, cuya implementación podría contribuir a que la articulación de estudios deje de ser un conjunto de acciones individuales de ciertas instituciones, para transformarse en una política de educación superior.

\section{Referencias bibliográficas}

Álamos, M.P. (2002) La formación Técnica Superior en Chile. Ministerio de Educación, Boletín n. ${ }^{\circ}$ 3, MECESUP. Chile, pp. 4-14.

Bendersky, S. (2009) La importancia de un Marco de Cualificaciones para la Educación Superior en Chile. Presentación. MINEDUC. 10 noviembre 2009. En: http://chcportal.mineduc.cl/marcoCualificaciones/ Fundamentos\%20para\%20Marco\%20de\%20cualificaciones/ Presentacion\%20de\%20Sally\%20Benderky\%20Divesup.pdf. 
88 ARTICULACIÓN DEL SISTEMA DE EDUCACIÓN SUPERIOR EN CHILE: POSIBILIDADES, TENSIONES Y DESAFÍOS - Marcela Gaete, Raquel Morales

Bernasconi, A. (2006) Dónde no somos tigres. Problemas de la formación Técnica en Chile en el contexto Latinoamericano. EN FOCO (72). Santiago. Expansiva, pp. 14-16.

Díaz Villa, M. (2002) Flexibilidad y Educación Superior en Colombia. Bogotá: ICFES, pp. 29-70.

Kremerman, M. (2005) Crisis en el sistema de educación superior en Chile: análisis y propuestas. Registro de Problemas Públicos (17). Santiago: Fundación Terram, pp. 15-25

Malagón, L.A. (2004) El currículo: dispositivo pedagógico para la vinculación universidad sociedad. Revista Electrónica de la Red de Investigación Educativa [en línea]. Vol. 1, n. ${ }^{\circ} 1$ (julio-diciembre). Disponible en $<$ http://revista.iered.org $>$.

Martínez, P. (2006) El Método de Estudio de Caso. Estrategia metodológica de la investigación Científica. Pensamiento \& Gestión, (20). Universidad del Norte, 165 -193.

Meller, P. y Rappoport, D. (2004) Comparaciones internacionales de la dotación de profesionales y la posición relativa chilena. En: Brunner, J.J. y Meller, P. (comps.) Oferta y demanda de profesionales y técnicos en Chile. Santiago de Chile: RIL Editores, pp. 231-233.

Ministerio de Educación, Chile. Informe: Bases para una Política de Formación Técnico-Profesional en Chile (2009) Disponible en: www.mineduc. cl/.../Formacion\%20Tecnica/Informe_basesFormTecnProf_Chile2009. pdf.

Ministerio del Trabajo y Asuntos Sociales. Instituto Social de las Cualificaciones. Sistemas Nacionales de Cualificaciones y Formación Profesional (2003) Madrid. Disponible en http://www.educacion.gob.es/educa/incual/ ice_ncfp.html.

Neto Caraveo, L.M. (2002) La flexibilidad curricular en la educación superior. Conferencia Magistral XXXII Reunión Nacional de Directores de la Asociación Mexicana de Educación Agrícola Superior (AMEAS), 24-26 octubre de 2002. México. Disponible en: http://ambiental.uaslp.mx/ docs/LMNC-PN-0210-FlexCurr.pdf.

OCDE e INCUAL (2008) Sistemas de Cualificaciones. Puentes para el aprendizaje a lo largo de la vida. Madrid: INCUAL; OCDE.

OCDE y Ministerio de Educación Chile. La Educación Superior en Chile (2009) Disponible en http://www.ubiobio.cl/varios/loreto/La_educacion_ Superior_en_Chile.pdf.

Salazar, J.M. (2005) Estudio sobre la Educación Superior no Universitaria en Chile. Informe IESALC/UNESCO. Secretaría de Educación Superior e 
Investigación Científica (SESIC). Disponible en http://unesdoc.unesco. org/images/0014/001404/140427s.pdf.

Stake, R. E. (1998) Investigación con estudio de casos. Madrid: Morata.

UNESCO. (1998) Declaración mundial sobre la educación superior en el siglo XXI: visión y acción. Disponible en: http://www.unesco.org/education/ educprog/.../declaration_spa.htm

Uribe, D. (2004) Oferta educativa y oferta de graduados de educación superior. En: Brunner, J.J. y Meller P. (comps.). (2004) Oferta y demanda de profesionales y técnicos en Chile. Santiago de Chile: RIL Editores, pp. 153-160.

Recibido: 10/05/2011

Aceptado: 1/08/2011 